\title{
Lessons from intensified surveillance of viral hepatitis A, Israel, 2017 and 2018
}

Yael Gozlan ${ }^{1}$, Itay Bar-Or ${ }^{1}$, Hadar Volnowitz ${ }^{1}$, Efrat Asulin ${ }^{1}$, Rivka Rich² , Emilia Anis ${ }^{2,3}$, Yonat Shemer ${ }^{4}$, Moran Szwarcwort Cohen $^{5}$, Etti Levy Dahary ${ }^{6}$, Licita Schreiber ${ }^{7}$, Ilana Goldiner ${ }^{8}$, Orit Rozenberg ${ }^{9}$, Orit Picard ${ }^{10}$, Michal Savion ${ }^{11}$, Inbal Fuchs ${ }^{12}$, Ella Mendelson $1,13,14$, Orna Mor ${ }^{1,13,14}$

1. Central Virology Laboratory, Ministry Of Health, Sheba Medical Center, Ramat-Gan, Israel

2. Public Health Services, Ministry Of Health, Jerusalem, Israel

3. Hebrew University Hadassah Braun School of Public Health and Community Medicine, Jerusalem, Israel

4. Virology Laboratory, Soroka University Medical Center, Beer-Sheva, Israel

5. Virology Laboratory, Rambam Health Care Campus, Haifa, Israel

6. Meuhedet Health Services, Lod, Israel

7. Maccabi Health Services, Mega Laboratory, Rehovot, Israel

8. Clinical Biochemistry Laboratory, Tel-Aviv Sourasky Medical Center, Tel-Aviv, Israel

9. Immunological Laboratory, Emek Medical Center, Afula, Israel

10. Gastroenterology Laboratory, Sheba Medical Center, Ramat Gan, Israel

11. Tel-Aviv District Health Office, Ministry Of Health, Tel Aviv, Israel

12. Clalit Health Services, Southern district Beer Sheva, Israel

13. School Of Public Health, Tel Aviv University, Tel Aviv, Israel

14. These authors contributed equally to this article

Correspondence: Orna Mor (orna.mor@sheba.health.gov.il)

Citation style for this article:

Gozlan Yael, Bar-Or Itay, Volnowitz Hadar, Asulin Efrat, Rich Rivka, Anis Emilia, Shemer Yonat, Szwarcwort Cohen Moran, Dahary Etti Levy, Schreiber Licita,

Goldiner Ilana, Rozenberg Orit, Picard Orit, Savion Michal, Fuchs Inbal, Mendelson Ella, Mor Orna. Lessons from intensified surveillance of viral hepatitis A, Israel, 2017 and 2018. Euro Surveill. 2021;26(6):pii=2000001. https://doi.org/10.2807/1560-7917.ES.2021.26.6.2000001

Introduction: Universal vaccination of toddlers has led to very low hepatitis A (HAV) endemicity in Israel. However, sporadic outbreaks still occur, necessitating better surveillance. Aim: To implement a comprehensive HAV surveillance programme. Methods: In 2017 and 2018, sera from suspected HAV cases that tested positive for anti-HAV IgM antibodies were transferred to the Central Virology Laboratory (CVL) for molecular confirmation and genotyping. Sewage samples were collected in Israel and Palestine ${ }^{\star}$ and were molecularly analysed. All molecular (CVL), epidemiological (District Health Offices and Epidemiological Division) and clinical (treating physicians) data were combined and concordantly assessed. Results: Overall, 146 cases ( 78 in 2017 and 68 in 2018, median age 34 years, 102 male) and 240 sewage samples were studied. Most cases (96\%) were unvaccinated. In $2017,89 \%$ of cases were male, $45 \%$ of whom were men who have sex with men (MSM). In $2018,49 \%$ were male, but only $3 \%$ of them were MSM (p<0.01). In 2017, $82 \%$ of cases and $63 \%$ of sewage samples were genotype $1 \mathrm{~A}$, phylogenetically associated with a global MSM-HAV outbreak. In 2018, $80 \%$ of cases and $71 \%$ of sewage samples were genotype $1 \mathrm{~B}$, related to the endemic strain previously identified in Israel and Palestine*. Environmental analysis revealed clustering of sewage and cases' sequences, and country-wide circulation of HAV. Conclusions: Molecular confirmation of HAV infection in cases and analysis of environmental samples, combined with clinical and epidemiological investigation, may improve HAV surveillance. Sequence-based typing of both clinical and sewage-derived samples could assist in understanding viral circulation.

\section{Introduction}

Hepatitis A virus (HAV) is the most common cause of viral hepatitis worldwide. It is transmitted primarily via the faecal/oral route by ingestion of contaminated food or water, or through direct contact with an infectious person. Infection does not result in chronic liver disease, but can cause debilitating symptoms and lead to acute liver failure, which is associated with high mortality [1]. In low-income countries, HAV remains highly endemic, but improvements in water and sanitation systems are reducing transmission rates. In many European countries, as well as in the United States (US) and other countries with effective sanitation and hygiene practices, HAV endemicity is low and the antiHAV vaccine-which was, for example, approved by the US Food and Drug Administration in 1995 [2]-is most often recommended to individuals at increased risk of infection and to cases' contacts [3]. In such countries, non-vaccinated adults remain susceptible to HAV and in recent years, outbreaks have become more frequent [4].

Visiting an endemic country 2 to 6 weeks before the onset of symptoms is one of the main risks for acquiring infection with HAV. In a study reporting causes of HAV infection in 13 European countries, $27.8 \%$ of reported hepatitis A cases between 2009 and 2015 were travel associated [5]. HAV outbreaks among MSM have been 
reported in European [6] and other countries [7-9], and-to a much lesser degree-in association with consumption of imported HAV-contaminated food [10].

In Israel, a country with a universal anti-HAV childhood vaccination programme since 1999-wherein children are vaccinated with two doses, at 1.5 and 2 years-two outbreaks were reported in the last 10 years. The first occurred in 2012 and 2013 among an unvaccinated homeless population in the Tel Aviv district [11]. The second, which started towards the end of 2016, was also mainly restricted to the Tel Aviv district. Unlike the previous outbreak, the latter involved non-vaccinated MSM, among whom HAV was primarily transmitted via sexual contacts, similar to the MSM outbreaks in Europe [12].

The HAV genome is a $7.5 \mathrm{~kb}$ ssRNA, non-enveloped, acid and heat stable picornavirus. The most common genotypes in humans are 1 and 3, which are divided into 2 subgenotypes, $A$ and $B$, with distinctive geographical and risk group distribution. Genotype $3 A$ has been reported in India and the Central Asian Republics of the former Soviet Union [13], while specific strains of genotype $1 \mathrm{~A}$ were recently linked to a global HAV outbreak among MSM [6-9].

Diagnosis of acute hepatitis $A$ is usually based on clinical signs consistent with acute viral hepatitis (e.g. fever, headache, malaise, anorexia, nausea, vomiting, diarrhoea, abdominal pain, abnormal liver function tests) together with the detection of anti-HAV IgM antibodies in the blood. Molecular analysis is not globally required for confirmation of HAV diagnosis. In the European Union, hepatitis $A$ is a notifiable disease; although repeat testing or molecular confirmation are not always performed, harmonisation of HAV typing practices was initiated in 2014 [14]. A recent report demonstrates that not all European countries perform centralised sample collection, making it challenging to compare HAV sequences in cases of cross-border HAV outbreaks [15].

Environmental surveillance for polio, a vaccine-preventable enteric virus, has demonstrated the ability to detect silent introduction of wild type poliovirus in the absence of clinical cases $[16,17]$. In Italy, surveillance of HAV in urban sewage demonstrated consistency with the classification of Italy as a low/intermediate endemic country [18].

The most recent HAV outbreak in Israel raised the need for better national HAV surveillance. Until this outbreak, diagnosis of HAV was based on the clinical picture of acute hepatitis and anti-HAV IgM positivity. Since 2017, molecular confirmation of HAV serology and sampling from major sewage treatment facilities throughout Israel were introduced. We describe the results obtained by this intensified surveillance programme in 2017 and 2018, as well as the lessons learnt.

\section{Methods}

Study design, clinical samples and data collection

This observational study was based on data collected between January 2017 and December 2018.

In Israel, hepatitis A cases are reported to the Ministry of Health $(\mathrm{MoH})$, as mandated by the State Public Health Law. Clinicians inform the district health offices (DHS) of a suspected case. The DHS conducts epidemiological investigations using a structured questionnaire and notifies the epidemiological division (ED) of public health services (PHS), which holds a database of all HAV infection cases (HAV registry).

Prior to this study, IgM-positive serology was the only result directly related to $\mathrm{HAV}$ that was used to confirm HAV infection. Since January 2017, PHS requested that molecular confirmation be performed at the viral hepatitis reference centre in the Central Virology Laboratory $(\mathrm{CVL})$, at Sheba Medical Center, Ramat Gan. District laboratories identifying blood samples positive for anti-HAV IgM antibodies ( $>1.2 \mathrm{~s} / \mathrm{co}$, Architect, Abbott, US) or with grey zone IgM results (0.8-1.2 s/co) were requested to transfer the remains of these sera samples to the CVL for molecular confirmation. When serum remains were not available for molecular assessment, HAV status was determined based on the anti-HAV IgM results, the reports from the treating physicians and the epidemiological investigation provided by the DHS. Data was continuously collected and updated in the national HAV database. Chi-square or Fisher exact tests were used for statistical analysis. $P$ value was considered significant if it was lower than 0.01 .

\section{Case definition}

In this study, all cases that met the clinical HAV criteria, i.e. IgM anti-HAV positive and HAV-RNA positive by PCR, were considered HAV confirmed. IgM positive cases meeting clinical criteria that could not be confirmed molecularly because of a lack of samples were considered possible cases. However, if contact (e.g. household, travel to an endemic country, sexual) with a laboratory-confirmed HAV case 15 to 50 days before onset of symptoms could be established, these cases were considered HAV confirmed. Individuals meeting clinical criteria but lacking laboratory confirmation were excluded.

\section{Sewage sample collection}

Sewage samples were collected monthly, as part of the routine supplemental polio surveillance programme, from four major districts in Israel (Jerusalem, Tel Aviv, Haifa and Beer-Sheva) and from Tsfat. From Palestine* (including Gaza, Nablus and Hebron), samples were collected every 3-4 months. Each of the $500 \mathrm{~mL}$ sewage samples collected was concentrated to $3-5 \mathrm{~mL}$, as previously described [11]. 
TABLE 1

Characteristics of hepatitis A virus infection cases, Israel, 2017-2018 $(\mathrm{n}=146)$

\begin{tabular}{|c|c|c|c|c|c|c|c|}
\hline \multirow{2}{*}{ Characteristics } & \multicolumn{3}{|c|}{2017} & \multicolumn{3}{|c|}{2018} & \multirow{2}{*}{$p$ value } \\
\hline & $\mathrm{N}$ & All & $\%$ & $\mathrm{~N}$ & All & $\%$ & \\
\hline Male & 69 & 77 & 89 & 33 & 68 & 49 & $<0.01$ \\
\hline Hospitalised & 45 & 78 & 57 & 32 & 60 & 53 & 0.609 \\
\hline $\mathrm{MSM}^{\mathrm{a}}$ & 31 & 69 & 45 & 1 & 3 & 33 & $<0.01$ \\
\hline Hepatitis A vaccination $^{\mathrm{b}}$ & 4 & 53 & 8 & 1 & 60 & 2 & 0.185 \\
\hline \multicolumn{8}{|l|}{ Residence } \\
\hline Tel Aviv district & 37 & \multirow{5}{*}{78} & 47 & 12 & \multirow{5}{*}{68} & 18 & $<0.01$ \\
\hline Jerusalem district & 7 & & 9 & 15 & & 22 & 0.023 \\
\hline Haifa district & 8 & & 10 & 7 & & 10 & 0.985 \\
\hline Beer-Sheva district & 12 & & 15 & 12 & & 18 & 0.713 \\
\hline $\begin{array}{l}\text { Other or unknown } \\
\text { regions }\end{array}$ & 14 & & 18 & 22 & & 32 & 0.044 \\
\hline \multicolumn{8}{|l|}{ HAV genotype } \\
\hline $1 \mathrm{~A}$ & 41 & \multirow{3}{*}{50} & 82 & 6 & \multirow{3}{*}{47} & 13 & $<0.01$ \\
\hline $1 \mathrm{~B}$ & 8 & & 16 & 38 & & 80 & $<0.01$ \\
\hline 3 & 1 & & 2 & 3 & & 6 & 0.278 \\
\hline
\end{tabular}

HAV: hepatitis A virus; MSM: men who have sex with men.

a Self-identified as MSM.

${ }^{b}$ Cases who received post-exposure vaccination were considered as vaccinated.

\section{Hepatitis A virus molecular confirmation}

Total nucleic acids were extracted from $400 \mu \mathrm{L}$ of serum using NucliSENS easyMag (bioMérieux, Marcy-l'Étoile, France). Total nucleic acids extractions in concentrated sewage were preliminarily prepared with omnicleave endonuclease (epicenter, Lucigen, Middleton, US) to reduce the load of free nucleic acids in the samples. Then $300 \mu \mathrm{L}$ concentrated sewage were extracted using NucliSENS easyMag (bioMérieux). RealStar HAV real-time PCR assay (version 1.0, Altona diagnostics, Hamburg, Germany) or in-house PCR assay (described below for sequencing) were used for molecular confirmation of HAV infection.

\section{Hepatitis A virus sequencing and genotyping}

All real-time PCR-positive samples were genotyped using PCR product that covered a 460-nt fragment located within the $\mathrm{VP}_{1} / \mathrm{P}_{2} \mathrm{~A}$ region according to the HAVNET unified typing protocol [14]. Sequencing was performed as previously described [12]. HAV genotype was determined using the Hepatitis A Virus Automated Genotyping Tool [19].

\section{Phylogenetic analysis}

HAV nt sequences were cured and aligned to the M14707 reference sequence using the Open-gene system (Siemens, Malvern, US). Phylogenetic analysis was conducted using a neighbour-joining algorithm in MEGA, version 6, with 1,000 replicates for bootstrap testing. Representative reference nt sequences for various genotypes included in the phylogenetic analysis were the $\mathrm{MH}_{577314.1}$ for US genotype $1 \mathrm{~A}$, KX22869.1 for Egypt genotype 1B, AF314208.1 for China genotype 1A, X83302.1 for Italy genotype 1A,
V16-25801 VP1 for Germany genotype 1A, RIVM europride 2016 1A for Europride genotype 1A, MNo62164.1 for US genotype 1A, VRD521 521 1A for England genotype 1A, MGO49743.1 for São Paulo genotype $1 \mathrm{~A}$ and DQ991030.1 for India genotype 3A, all from GenBank. All sequences were deposited in the National Center for Biotechnology Information database, accession numbers MT570190 - MT570349.

\section{Ethical statement}

This study was approved by the Sheba Medical Centre Institutional Review Board (number SNC-54819).

\section{Results}

\section{Molecular confirmation of anti-HAV IgM positive results}

Sera remains of samples reactive for anti-HAV IgM antibodies $(n=193)$ were tested for the presence of HAV RNA. Molecular analysis revealed that all grey zone samples $(n=41)$ were HAV RNA negative. Furthermore, no clinical signs of HAV infection were reported by the treating physicians; therefore, these cases were excluded from further analysis. Moreover, six anti-HAV IgM positive cases (above $1.2 \mathrm{~s} / \mathrm{co}$; four in 2017 and two in 2018) were not confirmed molecularly. In these cases, epidemiological investigation could not support HAV infection; therefore, they were excluded from the analysis. All other cases with available sera for molecular analysis were confirmed as described below and HAV was sequenced and genotyped.

\section{Clinical hepatitis A virus infection cases}

We identified 146 cases of HAV infection: 78 in 2017 and 68 in 2018. Table 1 summarises the data for all HAV infection cases. The median age of all cases was 34 years. Only five $(3.4 \%)$ cases were $>65$ years old and $10(6.8 \%)$ were 20 years old, all born after 1999 , when the vaccination programme was implemented.

Family contacts accounted for $2.6 \%(2 / 78)$ of the cases in 2017, while in 2018 five family/work contacts accounted for $19.1 \%(13 / 68)$ of the HAV infections. Hospitalisation rates were relatively similar between the studied years: $57 \%$ in 2017 and $53 \%$ in 2018. However, in $2017,89 \%$ of the cases were male and $45 \%$ self-identified as MSM, while in 2018 only $49 \%$ were male and only $3 \%$ self-identified as MSM ( $p<0.01)$. While in 2017 most of the HAV cases ( $47 \%$ ) were from the Tel Aviv district, in 2018 only $18 \%$ were from this area $(p<0.01)$. On the other hand, the proportion of cases from the Jerusalem district was significantly higher in 2018 (22\%) compared with 2017 (9\%; $\mathrm{p}=0.023)$.

Several operational steps were taken in 2017 to curb the HAV outbreak among MSM. Information was disseminated on social media, leaflets explaining HAV transmission were distributed, free vaccination was offered and HAV cases' household and sexual contacts were sought. 
TABLE 2

Characteristics of sewage and clinical samples by district, (sub)genotype and year of collection, Israel and Palestine*, 2017-2018

\begin{tabular}{|c|c|c|c|c|c|c|}
\hline \multirow[b]{2}{*}{ District } & \multicolumn{3}{|c|}{ Sewage samples } & \multicolumn{3}{|c|}{ Case samples } \\
\hline & $\begin{array}{c}\text { HAV } \\
\text { (sub)genotype }\end{array}$ & $\begin{array}{c}2017 \\
(\mathrm{n})\end{array}$ & $\begin{array}{c}2018 \\
(n)\end{array}$ & $\begin{array}{c}\text { HAV } \\
\text { (sub)genotype }\end{array}$ & $\begin{array}{c}2017 \\
(\mathrm{n})\end{array}$ & $\begin{array}{c}2018 \\
\text { (n) }\end{array}$ \\
\hline \multirow{5}{*}{ Jerusalem } & $1 \mathrm{~A}$ & 3 & 0 & $1 \mathrm{~A}$ & 1 & 0 \\
\hline & $1 \mathrm{~B}$ & 0 & 8 & $1 \mathrm{~B}$ & 0 & 4 \\
\hline & UD & 2 & 1 & 3 & 0 & 0 \\
\hline & All positives & 5 & 9 & Samples sequenced & 1 & 4 \\
\hline & All samples & 36 & 36 & All cases recorded & 7 & 12 \\
\hline \multirow{5}{*}{ Tel Aviv } & $1 \mathrm{~A}$ & 20 & 2 & $1 \mathrm{~A}$ & 25 & 2 \\
\hline & $1 \mathrm{~B}$ & 0 & 6 & $1 B$ & 2 & 13 \\
\hline & UD & 5 & 0 & 3 & 1 & 0 \\
\hline & All positives & 25 & 8 & Samples sequenced & 28 & 15 \\
\hline & All samples & 41 & 38 & All cases recorded & 37 & 15 \\
\hline \multirow{5}{*}{ Haifa } & $1 \mathrm{~A}$ & 4 & 0 & $1 \mathrm{~A}$ & 1 & 2 \\
\hline & $1 \mathrm{~B}$ & 3 & 4 & $1 \mathrm{~B}$ & 2 & 2 \\
\hline & UD & 3 & 4 & 3 & 0 & 2 \\
\hline & All positives & 10 & 8 & Samples sequenced & 3 & 6 \\
\hline & All samples & 12 & 11 & All cases recorded & 8 & 7 \\
\hline \multirow{5}{*}{ Beer-Sheva } & $1 \mathrm{~A}$ & 4 & o & $1 \mathrm{~A}$ & 1 & 0 \\
\hline & $1 \mathrm{~B}$ & 0 & 1 & $1 \mathrm{~B}$ & 0 & 2 \\
\hline & UD & 1 & 1 & 3 & 0 & 0 \\
\hline & All positives & 5 & 2 & Samples sequenced & 1 & 2 \\
\hline & All samples & 12 & 12 & All cases recorded & 1 & 3 \\
\hline \multirow{5}{*}{ Tzfat } & $1 \mathrm{~A}$ & 0 & 0 & $1 \mathrm{~A}$ & 0 & 0 \\
\hline & $1 \mathrm{~B}$ & 2 & 1 & $1 \mathrm{~B}$ & 0 & 0 \\
\hline & UD & 2 & 0 & 3 & 0 & 0 \\
\hline & All positives & 4 & 1 & Samples sequenced & 0 & 0 \\
\hline & All samples & 12 & 11 & All cases recorded & 0 & 0 \\
\hline \multirow{5}{*}{ Other } & $1 \mathrm{~A}$ & NA & NA & $1 \mathrm{~A}$ & 13 & 2 \\
\hline & $1 \mathrm{~B}$ & NA & NA & $1 \mathrm{~B}$ & 4 & 17 \\
\hline & UD & NA & NA & 3 & 0 & 1 \\
\hline & All samples & NA & NA & Samples sequenced & 17 & 20 \\
\hline & All cases recorded & NA & NA & All cases recorded & 17 & 20 \\
\hline \multirow{5}{*}{ Palestine* } & $1 \mathrm{~A}$ & 0 & 0 & $1 \mathrm{~A}$ & NA & NA \\
\hline & $1 \mathrm{~B}$ & 5 & 4 & $1 \mathrm{~B}$ & NA & NA \\
\hline & UD & 1 & 0 & 3 & NA & NA \\
\hline & All positives & 6 & 4 & Samples sequenced & NA & NA \\
\hline & All samples & 9 & 10 & All cases recorded & NA & NA \\
\hline
\end{tabular}

HAV: hepatitis A virus; NA: not available; UD: undetermined genotype (HAV-positive samples).

All sewage samples and cases identified in 2017 and 2018 are presented.

* This designation shall not be construed as recognition of a State of Palestine and is without prejudice to the individual positions of the European Union Member States on this issue. 


\section{FIGURE 1}

Environmental and clinical hepatitis A virus surveillance, Israel, 2017-2018

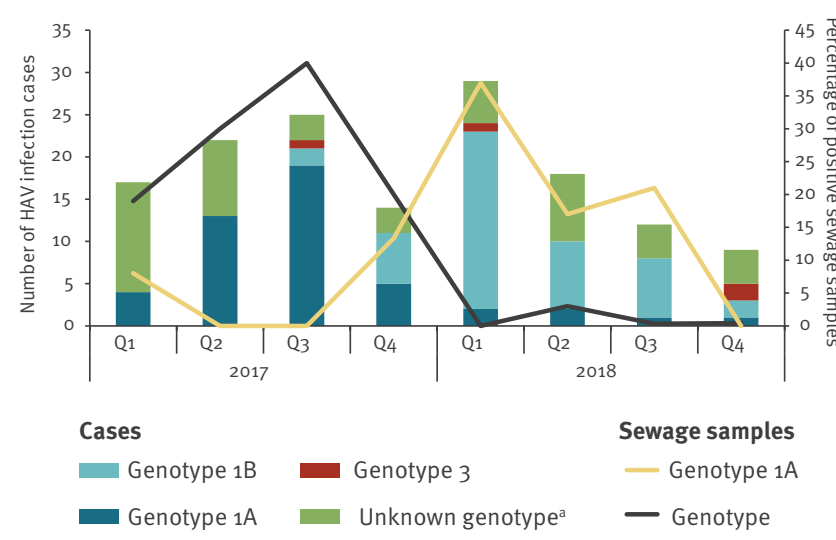

HAV: hepatitis A virus; Q: quarter.

a Those indicated as 'Unknown genotype' were cases considered as HAV positive, for whom blood samples were not available for molecular confirmation.

Most (96\%) of the cases in 2017 and 2018, including all those 20 years old, were not vaccinated. Epidemiological investigation revealed that three of those considered to have been vaccinated received the anti-HAV vaccine post-exposure. Date of vaccination was not available for the other two individuals.

Samples from 50 cases in 2017 and 47 cases in 2018 were available for molecular analysis. HAV genotype $1 \mathrm{~A}$ was found in 41 of 50 cases in 2017 and only in 6 of 47 cases in 2018 ( $p<0.01)$. Moreover, while in 2017 genotype $1 \mathrm{~B}$ was found in eight of 50 cases, in 2018,38 of 47 cases were infected with genotype $1 B$ ( $p<0.01$ ). Only a single case in 2017 and three cases in 2018 were found infected with genotype 3; all were travellers or had direct contact with travellers returning from endemic countries. Importation of genotype 1 was recorded for $40 \%$ of cases in 2017 and for $17 \%$ [8] of cases in 2018; $96 \%$ (27/28) of these had travelled to European countries and one to the US.

\section{Environmental surveillance}

A total of 240 sewage samples were assessed: 122 in 2017 and 118 in 2018 (Table 2). Nineteen of the samples (nine in 2017 and 10 in 2018) were collected from Palestine*. Overall, $45 \%(55 / 122)$ of sewage samples in 2017 and $27 \%(32 / 118)$ in 2018 were HAV positive ( $p<0.05)$. Reduction in the prevalence of HAV-positive sewage samples was mainly observed in the Tel Aviv district $(25 / 41,61 \%$ in 2017 vs $8 / 28,21 \%$ in 2018; $\mathrm{p}$ <0.01). Of note is the high percentage of HAV-positive sewage samples from the Haifa district in both 2017 (83\%) and 2018 (72\%), although the Haifa district was not the epicentre of any outbreak in these years. Genotype could be determined for $77 \%(67 / 87)$ of the HAV-positive sewage samples. In 2017 , the more frequent subgenotype was $1 \mathrm{~A}(31 / 55)$, while in 2018 subgenotype $1 \mathrm{~B}$ was dominant (24/32; $\mathrm{p}=0.108)$. HAV genotype 3 was not found in any of the sewage samples. All successfully sequenced sewage samples collected in Palestine* (9/19) were classified as subgenotype $1 \mathrm{~B}$.

\section{Comparison between clinical cases and environmental results}

The segregation of HAV-positive samples by (sub) genotype $(1 A, 1 B, 3$ or undetermined), geographical location and year of collection (Table 2) was highly similar between environmental samples and clinical cases. This observation is supported by the similarity between the timely pattern of HAV cases' diagnosis, detection of positive sewage samples and the type of viral genotypes that were identified throughout 2017 and 2018 (Figure 1). While information on HAV cases in Palestine* is not available to the PHS (Table 2), about half of sewage samples collected from facilities in

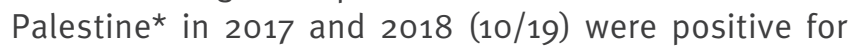
subgenotype $1 \mathrm{~B}$.

\section{Phylogenetic analysis}

Phylogenetic analysis revealed clustering of sewage and clinical samples both in 2017 and in 2018 (Figure 2). In 2017, the large cluster of subgenotype $1 \mathrm{~A}-$ which included both clinical and sewage sequences-aligned with both of the strains that were reported in MSM outbreaks in Europe: the RIVM europride $20161 \mathrm{~A}$ and the VRD 521 1A [6]. Clusters of $1 B$ in both 2017 and 2018 aligned with the $M 147071 \mathrm{~B}$ strain that was previously reported to be circulating in Israel [11]. Also, HAV $1 B$ sequences from all environmental samples clustered together with $1 \mathrm{~B}$ sequences identified in cases from different regions in the country, as well as with those previously reported to be circulating in Israel [11].

\section{Proposed model for hepatitis A virus surveillance}

Based on the findings presented, a model that outlines the diagnostic steps and the personnel required for efficient surveillance in low endemic countries is hereby suggested (Figure 3).

\section{Discussion}

This study demonstrates the added value of molecular and sequencing analysis of both clinical and environmental samples for the surveillance of an enteric virus like HAV.

In Israel, HAV incidence was below 0.7 cases per 100,000 population in the years prior to the study period ( 54 cases in 2014, 53 in 2015, 51 in 2016). Higher numbers of cases were reported in $2017(n=78)$ and $2018(n=68)$. In 2017, our data showed that the HAV 1 A outbreak among MSM in Israel accounted for this higher incidence. In contrast, the number of HAV $1 \mathrm{~B}$ cases in 2017 was much lower than in 2018 , when $1 \mathrm{~B}$ was the dominant subgenotype. Under-reporting of sporadic cases, mainly in 2017-when this enhanced surveillance system and data sharing between the CVL and ED had only recently been established, with most efforts directed towards stopping the subgenotype $1 \mathrm{~A}$ outbreak-may account for this low $1 \mathrm{~B}$ incidence. 


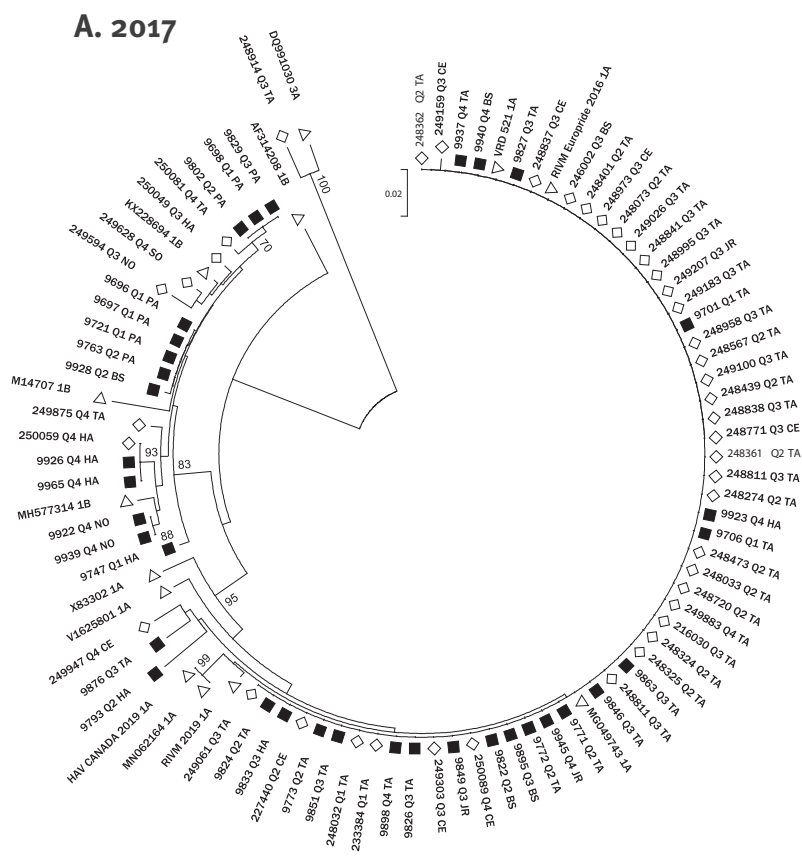

\section{B. 2018}

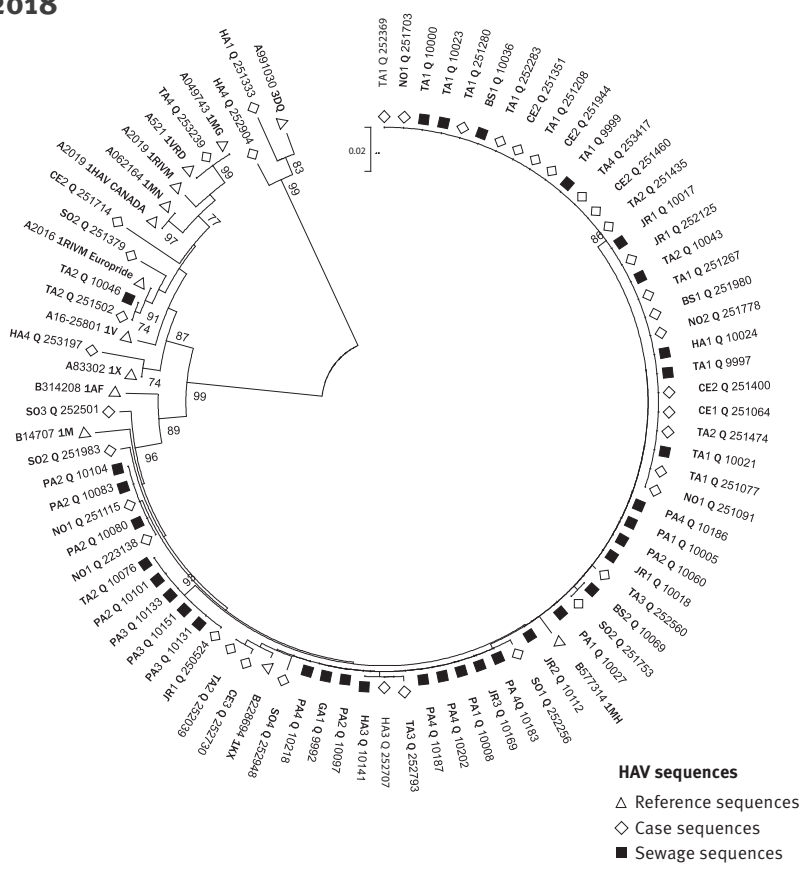

BS: Beer-Sheva; CE: central; HA: Haifa; JR: Jerusalem; NO: north; PA: Palestine*; Q: quarter; SO: south; TA: Tel Aviv.

Neighbour-joining tree of sequences of the VP1/P2A region (A- $428 \mathrm{bp}, \mathrm{B}-461 \mathrm{bp}$ ) of HAV isolates. Several reference strains (denoted by GeneBank accession number) were also included. Numbers at the nodes indicate bootstrap values. Each sequence is presented with its sample number, time of diagnosis (yearly quarter, Q1-Q4) and location. Distance scale (0.02) denotes $2 \%$ difference between any two sequences.

* This designation shall not be construed as recognition of a State of Palestine and is without prejudice to the individual positions of the European Union Member States on this issue.

Epidemiological investigation further revealed that the few $1 B$ cases in 2017 and those in 2018 were sporadic, some of which were transmissions within unvaccinated families. Indeed, in 2019, when the aforementioned collaborative workflow continued to operate, more cases $(n=86)$ were reported and $88.6 \%$ of the molecularly confirmed cases were found to be subgenotype $1 \mathrm{~B}$ (data not shown). Such synergistic impact of collaboration between reporting systems was previously demonstrated in Catalonia, where combining the Statutory Disease Reports and Microbiological Reporting Systems improved the efficiency of HAV case detection [20].

Another aspect of the presented framework is the value of molecular confirmation of HAV infection. Specificity is a known obstacle in serology. For example, it is known that older HAV cases can have a non-specific increase of anti-HAV IgM levels. Here, molecular analysis confirmed all IgM results of the few cases $>65$ years old. Molecular analysis further revealed that two individuals with positive anti-HAV IgM sera were HAV-RNA negative. Follow-up epidemiological analysis corroborated these findings. Consequently, these individuals were not analysed here. Indeed, the US Centres for Disease Control and Prevention have reported that in 2017 and $2018,8-10 \%$ of IgM positive samples were not confirmed by RNA analysis [21]. In our study, several of the IgM positive cases ( 28 in 2017 and 21 in 2018) were not molecularly tested due to logistical issues or lack of appropriate serum samples. Lack of molecular confirmation of all clinical cases is one of the limitations of our study. However, epidemiological investigation revealed that the vast majority of these cases, described herein, had been exposed to HAV (e.g. via importation, food contamination, sexual contacts), therefore indicating that all had genuine HAV infections.

HAV genotyping and phylogenetic analysis assists in transmission analyses during an outbreak investigation. In 2017, the majority of cases and many of the sewage samples were from the Tel Aviv district and were classified as subgenotype $1 \mathrm{~A}$, which was in agreement with the reports on the specific MSM HAV strains reported in the outbreaks in Europe in 2016 and 2017 [6]. These results, together with the demographic data and epidemiological investigation, indicated that the source of the outbreak in Israel was indeed European. In 2018, when the MSM outbreak had been controlled, the dominant subgenotype identified in cases from Tel Aviv-as well as from other districts-was 1B (and not $1 \mathrm{~A})$, which clustered with $1 \mathrm{~B}$ sequences found previously in Israel [11]. 


\section{FIGURE 3}

Proposed model for hepatitis A virus surveillance in countries with childhood vaccination programmes

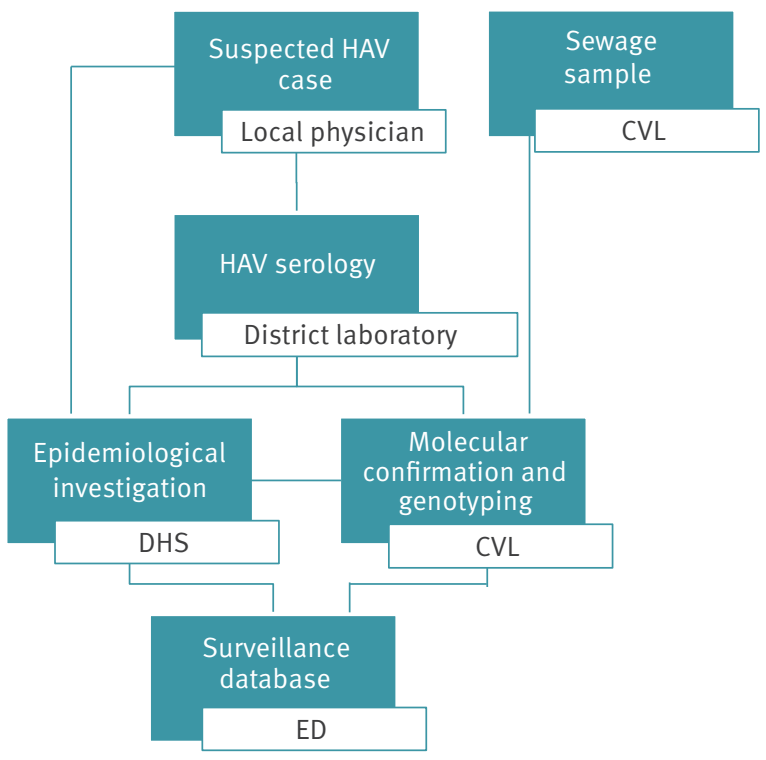

CVL: Central Virology Laboratory, Ministry of health; DHS: district health offices; ED: epidemiological division of public health services at the Ministry of health; HAV: hepatitis A virus.

The impact of environmental sampling for studying the circulation of an enteric virus is also demonstrated in this study. The most abundant strains of HAV subgenotypes $(1 \mathrm{~A}$ and $1 \mathrm{~B})$ identified in sewage and in clinical cases clustered together. Bisseux et al., in France, have also shown that environmental surveillance detected viral sequences that were genetically similar to those reported in clinical specimens [22]. Moreover, the correlation of time, place and prevalence of different HAV genotypes between the cases' and the environmental samples suggests that the latter can provide vital information on the circulation of enteric viruses such as $\mathrm{HAV}$ in countries where clinical cases are rare or underreported. Detection of pathogenic viruses in sewage has also been shown to provide an early warning of HAV and norovirus outbreaks [23].

Israel experienced silent circulation of wild poliovirus type 1 in 2013 and 2014, detected through environmental surveillance of the sewage system with no cases of acute flaccid paralysis [24]. In this study, about half of the sewage samples in Palestine* were HAV positive and $1 \mathrm{~B}$ was the only (sub)genotype identified, suggesting continuous circulation of this strain within the local population. Moreover, the Palestine*-derived $1 \mathrm{~B}$ sequences clustered with all $1 B$ sequences identified in this study, as well as those previously reported to be circulating in Israel and Palestine* [11]. Although clinical cases in Palestine* are not reported to the Israeli PHS, our results suggest that HAV $1 B$ is endemic in Palestine* and in our region, and strains need continuous monitoring.

There are several limitations to environmental surveillance. One of the drawbacks is its rather low sensitivity.
Even if sewage samples are found to be HAV negative, members of the population might still be infected and secrete enteric viruses [25]. It has been estimated that in industrialised communities, ca $1 \%$ of the population need to excrete the virus in order for it to be detected by sewage surveillance [17]. Indeed, genotype 3 , which was identified in only a few cases each year, was not detected in sewage, probably due its very low prevalence in the local population. Functional analysis was also not included in this study. Functional data, obtained by assessing the cytopathic effect of the environmental samples in tissue culture, would have ascertained the potential infectivity of the sewage-derived HAV sequences. However, HAV rarely grows in cell culture and requires several weeks to months in culture before it can be detected [26]. Another drawback of using a molecular approach to the analysis of sewage samples was raised in a study from Italy, where the variants restricted to detections in sewage samples were related to strains involved in past outbreaks [27]. Here, the environmental and clinical data showed the same trend, arguing against such a possibility. The cost-effectiveness of sewage surveillance, which was not investigated here, should also be considered, especially in countries without an established environmental sampling programme. Lastly, current sewage surveillance methodology does not cover all regions in Israel. For example, samples from facilities around the centre (e.g Hasharon and Ashdod) are not regularly collected. Expanding sewage sampling to other areas in the country would be beneficial.

\section{Conclusion}

In regions such as Israel that have low HAV incidence, molecular confirmation and phylogenetic analysis performed simultaneously with clinical and epidemiological investigation of all suspected cases could hasten identification of an outbreak. Once an outbreak is identified, measures to contain it can be implemented instantly. Ongoing analysis of environmental samples could improve the overall quality of surveillance in countries with national HAV vaccination programmes.

\section{Note}

*This designation shall not be construed as recognition of a State of Palestine and is without prejudice to the individual positions of the European Union Member States on this issue.

\section{Conflict of interest}

None declared.

\section{Authors' contributions}

YG and OM initiated the study, coordinated the data collection, performed data analysis and wrote the manuscript.

IBO and EA sampled and extracted sewage samples.

HV was involved in molecular and phylogenetic analysis. 
RR and EA collected, managed and coordinated epidemiological data and wrote a critical review.

YS, MSC, ELD, LS, IG, OP and OR were involved in clinical sample collection and serological analysis.

MS and IF collected, managed and coordinated clinical information.

EM contributed to the study design and wrote a critical review.

\section{References}

1. Lavanchy D. Viral hepatitis: global goals for vaccination. J Clin Virol. 2012;55(4):296-302. https://doi.org/10.1016/j. jcv.2012.08.022 PMID: 22999800

2. American Academy of Pediatrics Committee on Infectious Diseases. Hepatitis A vaccine recommendations. Pediatrics. 2007;120(1):189-99, https://doi.org/10.1542/peds.2007-1088 PMID: 17606579

3. Lemon SM, Ott JJ, Van Damme P, Shouval D. Type A viral hepatitis: A summary and update on the molecular virology, epidemiology, pathogenesis and prevention. J Hepatol. 2017;S0168-8278(17)32278-X. PMID: 28887164

4. Jacobsen KH. Globalization and the Changing Epidemiology of Hepatitis A Virus. Cold Spring Harb Perspect Med. 2018;8(10):a031716. https://doi.org/10.1101/cshperspect. a031716 PMID: 29500305

5. Beauté J, Westrell T, Schmid D, Müller L, Epstein J, Kontio M, et al. Travel-associated hepatitis A in Europe, 2009 to 2015. Euro Surveill. 2018;23(22):1700583. https://doi.org/10.2807/15607917.ES.2018.23.22.1700583 PMID: 29871720

6. Ndumbi P, Freidl GS, Williams CJ, Mårdh O, Varela C, Avellón A, et al. Hepatitis A outbreak disproportionately affecting men who have sex with men (MSM) in the European Union and European Economic Area, June 2016 to May 2017. Euro Surveill. 2018;23(33):1700641. https://doi.org/10.2807/1560-7917. ES.2018.23.33.1700641 PMID: 30131095

7. Sachdeva H, Benusic M, Ota S, Stuart R, Maclachlan J, Dubey $V$, et al. Community outbreak of hepatitis A disproportionately affecting men who have sex with men in Toronto, Canada, January 2017-November 2018. Can Commun Dis Rep. 2019;45(10):262-8. https://doi.org/10.14745/ccdr.v45i10ao3 PMID: 31647057

8. Chen WC, Chiang PH, Liao YH, Huang LC, Hsieh YJ, Chiu CM, et al. Outbreak of hepatitis A virus infection in Taiwan, June 2015 to September 2017. Euro Surveill. 2019;24(14):1800133. https://doi.org/10.2807/1560-7917.ES.2019.24.14.1800133 PMID: 30968822

9. Rivas V, Barrera A, Pino K, Núñez R, Caceres CJ, Lopez-Lastra $M$, et al. Hepatitis A outbreak since November 2016 affecting men who have sex with men (MSM) in Chile connected to the current outbreak in MSM in Europe, situation up to October 2017. Euro Surveill. 2018;23(9):1800060. https:// doi.org/10.2807/1560-7917.ES.2018.23.9.18-00060 PMID: 29510780

10. Foster MA, Hofmeister MG, Kupronis BA, Lin Y, Xia GL, Yin S, et al. Increase in Hepatitis A Virus Infections - United States, 2013-2018. MMWR Morb Mortal Wkly Rep. 2019;68(18):413-5. https://doi.org/10.15585/mmwr.mm6818a2 PMID: 31071072

11. Manor Y, Lewis M, Ram D, Daudi N, Mor O, Savion M, et al. Evidence for Hepatitis A virus endemic circulation in Israel despite universal toddlers' vaccination since 1999 and low clinical incidence in all age groups. J Infect Dis. 2016;jiw611. PMID: 28013247

12. Gozlan Y, Bar-Or I, Rakovsky A, Savion M, Amitai Z, Sheffer R, et al. Ongoing hepatitis A among men who have sex with men (MSM) linked to outbreaks in Europe in Tel Aviv area, Israel, December 2016 - June 2017. Euro Surveill. 2017;22(29):30575. https://doi.org/10.2807/1560-7917.ES.2017.22.29.30575 PMID: 28749336

13. Nainan OV, Xia G, Vaughan G, Margolis HS. Diagnosis of hepatitis a virus infection: a molecular approach. Clin Microbiol Rev. 2006;19(1):63-79. https://doi.org/10.1128/ CMR.19.1.63-79.2006 PMID: 16418523

14. National Intitute for Public Health and Environment (RIVM). Molecular detection and typing of VP1 region of HAV. Protocol. Bilthoven: RIVM; 2018. Available from: https://www.rivm. $\mathrm{nl} /$ sites/default/files/2018-11/Typing\%2oprotocol\%20 HAVNET\%20VP1P2A\%20a1a.pdf

15. Enkirch T, Severi E, Vennema H, Thornton L, Dean J, Borg ML, et al. Improving preparedness to respond to cross-border hepatitis A outbreaks in the European Union/ European Economic Area: towards comparable sequencing of hepatitis A virus. Euro Surveill. 2019;24(28). https:// doi.org/10.2807/1560-7917.ES.2019.24.28.1800397 PMID: 31311618

16. Patel JC, Diop OM, Gardner T, Chavan S, Jorba J, Wassilak SGF, et al. Surveillance to Track Progress Toward Polio Eradication - Worldwide, 2017-2018. MMWR Morb Mortal Wkly Rep. 2019;68(13):312-8. https://doi.org/10.15585/mmwr.mm6813a4 PMID: 30946737

17. Manor Y, Handsher R, Halmut T, Neuman M, Bobrov A, Rudich $\mathrm{H}$, et al. Detection of poliovirus circulation by environmental surveillance in the absence of clinical cases in Israel and the Palestinian authority. J Clin Microbiol. 1999;37(6):16705. https://doi.org/10.1128/JCM.37.6.1670-1675.1999 PMID: 10325305

18. La Rosa G, Libera SD, Iaconelli M, Ciccaglione AR, Bruni R, Taffon S, et al. Surveillance of hepatitis A virus in urban sewages and comparison with cases notified in the course of an outbreak, Italy 2013. BMC Infect Dis. 2014;14(1):419. https://doi.org/10.1186/1471-2334-14-419 PMID: 25074676

19. National Institute for Public Health and the Environment (RIVM). Hepatitis A Virus Genotyping Tutorial. Bilthoven: RIVM. [Accessed: 27 Feb 2019]. Available from: https://www.rivm.nl/ $\mathrm{mpf} /$ typingtool/hav/how-to-use

20. Carmona G, Vilaró M, Ciruela P, Jané M, Giralt L, Ruiz L, et al. Hepatitis A surveillance: sensitivity of two information sources. BMC Infect Dis. 2018;18(1):633. https://doi.org/10.1186/ S12879-018-3552-4 PMID: 30526527

21. Association of Public Health Laboratories (APHL). Hepatitis A Virus Testing and Resources. Silver Spring, MD: APHL; 2018. Available from: https://www.aphl.org/programs/infectious disease/Documents/2018_HAV_DiagnosticUpdate.pdf

22. Bisseux M, Colombet J, Mirand A, Roque-Afonso AM, Abravanel F, Izopet J, et al. Monitoring human enteric viruses in wastewater and relevance to infections encountered in the clinical setting: a one-year experiment in central France, 2014 to 2015. Euro Surveill. 2018;23(7). https:// doi.org/10.2807/1560-7917.ES.2018.23.7.17-00237 PMID: 29471623

23. Hellmér M, Paxéus N, Magnius L, Enache L, Arnholm B, Johansson A, et al. Detection of pathogenic viruses in sewage provided early warnings of hepatitis $A$ virus and norovirus outbreaks. Appl Environ Microbiol. 2014;80(21):6771-81. https://doi.org/10.1128/AEM.01981-14 PMID: 25172863

24. Manor Y, Shulman LM, Kaliner E, Hindiyeh M, Ram D, Sofer $D$, et al. Intensified environmental surveillance supporting the response to wild poliovirus type 1 silent circulation in Israel, 2013. Euro Surveill. 2014;19(7):20708. https://doi. org/10.2807/1560-7917.ES2014.19.7.20708 PMID: 24576473

25. Brouwer AF, Eisenberg JNS, Pomeroy CD, Shulman LM, Hindiyeh M, Manor Y, et al. Epidemiology of the silent polio outbreak in Rahat, Israel, based on modeling of environmental surveillance data. Proc Natl Acad Sci USA. 2018;115(45):E10625-33. https:// doi.org/10.1073/pnas.1808798115 PMID: 30337479

26. Konduru K, Kaplan GG. Stable growth of wild-type hepatitis A virus in cell culture. J Virol. 2006;80(3):1352-60. https://doi. org/10.1128/JVI.80.3.1352-1360.2006 PMID: 16415012

27. Pellegrinelli L, Galli C, Binda S, Primache V, Tagliacarne C Pizza F, et al. Molecular Characterization and Phylogenetic Analysis of Enteroviruses and Hepatitis A Viruses in Sewage Samples, Northern Italy, 2016. Food Environ Virol. 2019;11(4):393-9. https://doi.org/10.1007/s12560-019-09401-4 PMID: 31420848

\section{License, supplementary material and copyright}

This is an open-access article distributed under the terms of the Creative Commons Attribution (CC BY 4.0) Licence. You may share and adapt the material, but must give appropriate credit to the source, provide a link to the licence and indicate if changes were made.

Any supplementary material referenced in the article can be found in the online version.

This article is copyright of the authors or their affiliated institutions, 2021. 